\title{
Water-induced thermal Decomposition of Fireworks Gunpowder Chemical Composition
}

\author{
R. Manikandan, S. Rajesh, ${ }^{3}$ K.Subash
}

\begin{abstract}
In the firework industry, thermal decomposition is the main source of minor and fatal accidents. The existence of moisture and hygroscopic property of the fireworks chemical powders leads to thermal decomposition. In this study, firework chemicals combinations are modified by adding charcoal as one of the chemical powder. Here the gun powder is made using different chemical powders like potassium nitrate, sulfur, charcoal and it could be stored in shadow shed (stage-I) and followed by drying platform (stage-II). During this storage time, thermal analysis is carried out using Differential Scanning Calorimetric (DSC). DSC result of gun powder (after preparation) shows that thermal decomposition starts at $262.67^{\circ} \mathrm{C}$ and enthalpy is $-521.57 \mathrm{~J} / \mathrm{g}$. The gun powder from shadow shed it is $263.93^{\circ} \mathrm{C}$ and enthalpy is $-378.21 \mathrm{~J} / \mathrm{g}$. The onset temperature of the gun powder collected from the drying platform is $265.25^{\circ} \mathrm{C}$ and enthalpy is $-284.01 J / g$. The sample after preparation contains more amount of moisture content absorbs more heat and initiates the thermal decomposition as earlier than the sample collected from shadow shed and drying platform. The heat dissipation rate is also reduced for stage I than stage II. So, the thermal hazards associated manufacturing process is very high when it contains more amount of moisture content.
\end{abstract}

Keywords - Gun powder, thermal analysis, moisture content, DSC test

\section{INTRODUCTION}

$\mathrm{T}_{\mathrm{h}}$ particularly prone to have fires and explosions. In the fireworks industry, all the chemical powders are handling manually. The chemical powders are categorized as fuels, oxidizers, igniters based on their nature. These chemicals are very sensitive to friction, impact, and static charge. Nowadays, numerous accidents occurred in fireworks industries during processing, storage, and transportation of chemical powders [1] and also during handling of gun powder chemical mixture. It is due to friction, impact, mishandling, carelessness, and horseplay during handling of chemical powders. The atmospheric humidity level and moisture content are an important consideration for reducing the accident. The expose of safety and health hazards are very high during handling of chemical powders. Many fire and explosion accidents are occurred due to the

Revised Manuscript Received on December 05, 2019.

* Correspondence Author

R.Manikandan, Department of Mechanical engineering, Kalasalingam Academy of research and education, Krishnankoil-626126, India. Email: rmanikandan198@gmail.com

S.Rajesh*, Department of Mechanical engineering, Kalasalingam Academy of research and education, Krishnankoil-626126, India. Email: s.rajesh@klu.ac.in

K.Subash M.Tech (ISE), Department of Mechanical Engineering, Kalasalingam Academy of Research and Education, Virudhunagar, Email:subashy45@gmail.com aforementioned reason only. The firecrackers are used by age group people during Diwali and other major festivals. Firecrackers are available in different varieties namely, sparklers, chakker, fire, chorsa, atom bomb (bursting type), rocket, colour fountain, and aerial fireworks (fancy type). In this work, thermal analysis of the gun powder is studied. Gun powder is a mixture of charcoal, sulfur and potassium nitrate with distinct ratios. The chemical composition of the gun powder is $75 \%$ of Potassium Nitrate (KNO3), $10 \%$ of Sulfur (S) and $15 \%$ of charcoal [2]. Among the above charcoal acts as fuel and KNO3 and sulfur act as oxidizer and igniter. These chemical powders react with each other to form nitrogen and carbon dioxide gases and potassium sulfide during the combustion of chemical powders [3]. Differential scanning calorimeter (DSC) has been employed to understand the pyrotechnic compositions chemical reaction process. The ignition temperature is raised by adding sulfur content along with chemical composition [4]. In this work moisture content present in the gun powder analyzed by dry weight basis method. $15 \%$ amount of moisture content presented in between the stage of shadow shed and after preparation of cracker. The amount of moisture content available between the shadows shed to sunlight is $4.7 \%$. So $19.7 \%$ amount of moisture content is available in gun powder. This can influence the thermal decomposition easily 'if drying method can be changed.

Thermal characteristics of flower pot tip mixture are analyzed and it is observed that the thermal decomposition starts earlier than tip mixture with water content and the heat reaction is also very high for tip mixture with water content [5]. Thermal decomposition can occur self-sustaining combustion reaction during the storage process, generate $\mathrm{CO}_{2}, \mathrm{NO}_{2}$ gases and dissipate heat because of its chemical mixture characteristics. If the heat cannot be dissipated properly, it will accelerate the thermal decomposition, which will reduce the storage life and safety of the worker. The molten $\mathrm{KNO}_{3}$ propagate the gun powder combustion rate [6].In the air, sulfur oxidizes at temperatures below the melting-point of KNO3. Xu-Lin Chen et al (2002) observed that an explosion occurred during usage of a large amount of gun powder in at one time and also carelessness of worker during handling of chemical powders. [7].Aluminum nanopowders reactivity is influenced by atmospheric humidity [8]. The onset temperature of the gun powder chemical compositions are lower in different degree after humidification and the activation energy have reduced, as well as the thermal safety has been lower [9]. So the humidity is also one of the main factors should consider during handling, storage of the pyrotechnic chemical composition. So the worker should more attentive during handling of gun powder for avoiding the aforementioned accidents and make the working environment free from safety hazards. After preparing the gun powder it 
cannot be directed into the sunlight because of the generation of a large amount of heat generation and it leads to an accident. So after preparing the gun powder, it is stored into shadow shed for one day and next day it will be stored into drying platform. The drying platform position is directed into the sunlight for the removal of moisture content. The presence of moisture content varies for all the stages.

In this work, thermal behavior of the gun powder is analyzed during various storage condition and safety measures 'are given.

\section{MATERIALS AND MethodS}

The chemical powders are used in this work like $\mathrm{KNO}_{3}$, Sulfur and charcoal were obtained from Raj fireworks industry situated in southern Tamil Nadu, India. The purity of the $\mathrm{KNO}_{3}, \mathrm{C}$ and $\mathrm{S}$ are 97.6, 96 and 99.9\%. In this chemical powders, potassium nitrate act as an oxidizer that supplies oxygen for the combustion reaction. The source of carbon is given by charcoal. The sulfur acts as an igniter to provides the required temperature for ignition. The required amount of chemical powders are taken and the desired level of water is added with this chemical composition, it is mixed using a wooden tray in a non-flammable container and made a pellet shape. All the processes were done manually.

\section{A. Differential Scanning Calorimeter (DSC)}

Differential scanning Calorimetry is a thermo analytical technique and used to measure the heat flow and the model DSC 4000, Perkin Elmer is used to studying the thermal stability of various gun powder compositions. DSC consists of a sample chamber of $250 \mathrm{ml}$ capacity. The sample weight of $3.5 \mathrm{mg}$ is taken in an aluminum pan. The aluminum pan is sealed with an aluminum lid and placed in the sample thermocouple of the DSC chamber. It was heated at the temperature range from $10.00^{\circ} \mathrm{C}$ to $445.00^{\circ} \mathrm{C}$ at a constant rate of $10^{\circ} \mathrm{C} / \mathrm{min}$.

\section{B. Sensitivity analysis}

The sensitiveness of the gun powder composition in powder form and pellet shape is monitored for finding their impact and friction sensitivity property during handling. Impact sensitivity of pyrotechnic mixture is measured as per the procedures are given in German Federal Institute for Testing Materials (BAM-UN Test Series.3) and The friction sensitiveness is determined using a friction sensitivity machine by using common test methods of BAM [10]. A fixed load of $2 \mathrm{~kg}$ is falling from different heights to record the safe limiting impact energy of gun powder sample in powder and pellet form without flash. The impact sensitivity of the gun powder sample was expressed by limiting energy. The Limiting Impact Energy (LIE) can be calculated by, LIE = $\mathrm{mgh}$. Where $\mathrm{m}$ is the weight of the drop mass in $\mathrm{kg}$. $\mathrm{g}$ acceleration due to gravity $\left(9.81 \mathrm{~m} / \mathrm{s}^{2}\right) . \mathrm{h}$ - fall a height of the drop weight in meters $(\mathrm{m})$. The limiting impact energy is categorized by very sensitive, sensitive, insensitive and moderate. The limiting energy value is less than 5joules is called as very sensitive and between 5 and 20joules is known as a sensitive category. The limiting energy between 20 and 30 Joules is called as moderate. The limiting energy is more than 30 Joules is known as insensitive. Fireworks chemical mixture always comes under a sensitive and very sensitive category.

\section{RESULTS AND DISCUSSION}

DSC was carried out to access the thermal behavior of the gun powder chemical mixture during storage at various stages like immediately after preparation, shadow shed and drying platform with the influence of water.

\section{A. DSC tests for gun powder}

The DSC plots with gunpowder and $19.7 \%$ wt of water with gun powder are presented. The moisture content present in the gun powder is determined by subtracting the initial and final weight of gun powder and divided by the initial weight of the gun powder. It is observed that with the addition of water content, the heat dissipation rate is increased in the temperature range of 250 to $275^{\circ} \mathrm{C}$. The thermal decomposition (i.e.) exothermic reaction of the gun powder after preparation shows that onset temperature starts at $262.27^{\circ} \mathrm{C}$. It goes maximum at $266.49^{\circ} \mathrm{C}$ and comes end at $271.82^{\circ} \mathrm{C}$ and the heat released in this area is $-521.5766 \mathrm{~J} / \mathrm{g}$. The exothermic formation area is $2086.30 \mathrm{~mJ}$. After preparation of gun powder first endothermic starts at $86.89^{\circ} \mathrm{C}$ and it's due to the melting of sulfur content (phase transition from solid to liquid) and it is monoclinic crystals. The second decomposition also occurs at $111.92^{\circ} \mathrm{C}$ (rhombic crystals ) due to the melting of sulfur content. Generally, in physical state, two crystalline structures are available in Sulfur. There are rhombic ( $\alpha$-sulfur), and monoclinic ( $\beta$-sulfur). The sulfur melting point below $96^{\circ} \mathrm{C}$ is called as orthorhombic and the melting point range between $96^{\circ} \mathrm{C}$ and $119^{\circ} \mathrm{C}$ is known as monoclinic sulfur. The third decomposition starts at $320.42^{\circ} \mathrm{C}$ due to the melting of potassium nitrate from solid to liquid.

In stage-I (shadow shed) thermal decomposition of the gun powder from shadow shed starts at $263.93^{\circ} \mathrm{C}$. It goes maximum at $267.88^{\circ} \mathrm{C}$ and comes end at $272.04^{\circ} \mathrm{C}$ and the heat released in this area is $-378.21 \mathrm{~J} / \mathrm{g}$. The area under the formation of an exothermic reaction is $-1323.25 \mathrm{~mJ}$. Similarly for gun powder collected from shadow shed shows that the first and second endothermic decomposition occurs at 50.28 and $115^{\circ} \mathrm{C}$ by melting of sulfur content and the third decomposition occurs at $325^{\circ} \mathrm{C}$ by Endothermic - phase transition of $\mathrm{KNO} 3$. At $380^{\circ} \mathrm{C}$ decomposition occurs due to Exothermic - thermal decomposition of carbon content (loss of volatile constituent). The exothermic reaction occurs at $263.93^{\circ} \mathrm{C}$ by Exothermic - violent decomposition of gun powder.

In stage-2 (drying platform), the exothermic curve starts at $265.25^{\circ} \mathrm{C}$ goes maximum at $268.83^{\circ} \mathrm{C}$ and comes ends at $273.19^{\circ} \mathrm{C}$. The heat dissipation rate is $-284.0156 \mathrm{~J} / \mathrm{g}$. The formation of exothermic reaction in the area of $-994.0 \mathrm{~mJ}$. Gun powder collected from the drying platform observed that endothermic reaction at $52^{\circ} \mathrm{C}$ and $86^{\circ} \mathrm{C}$ due to the melting of sulfur content (phase transition). At $265.25^{\circ} \mathrm{C}$, the exothermic decomposition occurs by combustion of sulfur, potassium nitrate and charcoal. The Exothermic - thermal decomposition of carbon content occurs at $410^{\circ} \mathrm{C}$. The onset, end, decomposition temperature and heat content of gun 
powder reaction at various stages were summarized in Table. 1

Table-I: DSC test result for gun powder

\begin{tabular}{|l|c|c|c|c|c|}
\hline $\begin{array}{c}\text { Gun powder at } \\
\text { various stage }\end{array}$ & $\begin{array}{c}\text { Onset } \\
\left({ }^{\circ} \mathbf{C}\right)\end{array}$ & $\begin{array}{c}\text { Peak } \\
\left({ }^{\circ} \mathbf{C}\right)\end{array}$ & $\begin{array}{c}\text { End } \\
\left({ }^{\circ} \mathbf{C}\right)\end{array}$ & $\begin{array}{c}\text { Area } \\
(\mathbf{m J})\end{array}$ & $\begin{array}{c}\Delta \mathbf{H} \\
(\mathbf{J} / \mathbf{g})\end{array}$ \\
\hline After preparation & 262.27 & 268.83 & 271.82 & 2086.30 & -521.57 \\
\hline Shadow Shed & 263.93 & 267.88 & 272.04 & -1323.75 & -378.21 \\
\hline Drying platform & 265.25 & 266.49 & 273.19 & -994 & -284.01 \\
\hline
\end{tabular}
increases the evolution of heat content is than stage-2. The onset temperature was increased with an increase in peak the objectives of performing the DSC experiments were to examine the potential of these mixtures to show exothermic behavior. Since the samples showed exothermic behavior in the temperature range of $250-275^{\circ} \mathrm{C}$.

It is observed from the impact sensitivity test result, when applying a load of $2 \mathrm{kgs}$ at height of $0.9 \mathrm{~m}$, over the gun powder chemical mixture the flash has occurred. But the flash does not occur in gun powder pellet. Because of the moisture content present in the gun powder pellet, cannot ignite the chemical mixture. Similarly, the impact test is carried out at various heights. The impact sensitivity result is given in Table. 2

Table-II: Impact sensitivity results for gun powder in pellet $\&$ powder stage

\begin{tabular}{|c|c|c|c|c|c|c|c|c|c|}
\hline \multirow{2}{*}{$\begin{array}{c}\text { Gun } \\
\text { powder } \\
\text { /pellet }\end{array}$} & \multirow{2}{*}{$\begin{array}{c}\text { Load } \\
(\mathbf{m}) \\
\text { in } \\
\text { kg } \\
\end{array}$} & \multirow{2}{*}{$\begin{array}{c}\text { Heig } \\
\text { ht } \\
\text { (h) } \\
\text { in } \mathbf{~ m} \\
\end{array}$} & \multicolumn{6}{|c|}{ Number of Trials } & \multirow{2}{*}{$\begin{array}{c}\text { Limitin } \\
\mathrm{g} \text { energy } \\
\text { in J }\end{array}$} \\
\hline & & & 1 & 2 & 3 & 4 & 5 & 6 & \\
\hline Powder & 2.0 & 0.90 & $\checkmark$ & $\sqrt{ }$ & $\checkmark$ & $\checkmark$ & $\checkmark$ & $\checkmark$ & 17.65 \\
\hline Pellet & 2.0 & 0.90 & $X$ & $X$ & $X$ & $X$ & $X$ & $X$ & 17.65 \\
\hline Powder & 2.0 & 0.85 & $X$ & $X$ & $X$ & $X$ & $X$ & $X$ & 16.67 \\
\hline Pellet & 2.0 & 0.85 & $X$ & $\bar{X}$ & $X$ & $X$ & $X$ & $X$ & 16.67 \\
\hline Powder & 2.0 & 0.8 & $X$ & $X$ & $X$ & $X$ & $X$ & $X$ & 15.69 \\
\hline Pellet & 2.0 & 0.8 & $X$ & $\bar{X}$ & $X$ & $X$ & $X$ & $X$ & 15.69 \\
\hline Powder & 2.0 & 0.7 & $X$ & $X$ & $\bar{X}$ & $X$ & $X$ & $X$ & 13.73 \\
\hline Pellet & 2.0 & 0.7 & $X$ & $X$ & $X$ & $X$ & $X$ & $X$ & 13.73 \\
\hline Powder & 2.0 & 0.6 & $X$ & $X$ & $\bar{X}$ & $X$ & $X$ & $X$ & 11.77 \\
\hline Pellet & 2.0 & 0.6 & $X$ & $X$ & $X$ & $X$ & $X$ & $X$ & 11.77 \\
\hline
\end{tabular}

It is observed from the friction sensitivity test result when applying the maximum load of $360 \mathrm{~N}$ over the gun powder chemical mixture; the flash does not occur for both gun powder pellet and gun powder chemical mixture. Similarly, the frictional sensitivity test is carried out for both samples by
It indicates that high moisture content present in the sample exothermic activity during an increase in heating rate. Here

applying various loads. The sensitivity test result is given in Table. 3

Table -III: Friction Sensitivity Analysis for Gun Powder in pellet \& powder Stage

\begin{tabular}{|c|l|c|c|c|c|c|c|}
\hline \multirow{2}{*}{$\begin{array}{c}\text { Gunpowder } \\
\text { pellet/powder }\end{array}$} & \multirow{2}{*}{ Load (N) } & \multicolumn{7}{|c|}{ Number of Trials } \\
\cline { 3 - 8 } & & $\mathbf{1}$ & $\mathbf{2}$ & $\mathbf{3}$ & $\mathbf{4}$ & $\mathbf{5}$ & $\mathbf{6}$ \\
\hline Pellet & 360 & $\boldsymbol{X}$ & $\boldsymbol{X}$ & $\boldsymbol{X}$ & $\boldsymbol{X}$ & $\boldsymbol{X}$ & $\boldsymbol{X}$ \\
\hline Powder & 324 & $\boldsymbol{X}$ & $\boldsymbol{X}$ & $\boldsymbol{X}$ & $\boldsymbol{X}$ & $\boldsymbol{X}$ & $\boldsymbol{X}$ \\
\hline Pellet & 360 & $\boldsymbol{X}$ & $\boldsymbol{X}$ & $\boldsymbol{X}$ & $\boldsymbol{X}$ & $\boldsymbol{X}$ & $\boldsymbol{X}$ \\
\hline Powder & 324 & $\boldsymbol{X}$ & $\boldsymbol{X}$ & $\boldsymbol{X}$ & $\boldsymbol{X}$ & $\boldsymbol{X}$ & $\boldsymbol{X}$ \\
\hline
\end{tabular}

$X-$ Does not flash

The summarized friction and impact sensitivity test result for gunpowder sample in pellet and powder form are given in table. 4

Table -IV: Sensitivity analysis for Gun powder in pellet \& powder stage

\begin{tabular}{|l|c|c|c|c|}
\hline $\begin{array}{c}\text { S.N } \\
\mathbf{0}\end{array}$ & Pellet/Powder & Sample & $\begin{array}{c}\text { Impact } \\
\text { sensitivity } \\
\text { (Joules) }\end{array}$ & $\begin{array}{c}\text { Friction } \\
\text { sensitivity } \\
\text { (Newton) }\end{array}$ \\
\hline 1 & $\begin{array}{c}\text { Gun powder } \\
\text { Pellet } \\
\text { All Stages }\end{array}$ & $\begin{array}{c}\text { Gun } \\
\text { powder }\end{array}$ & Nil & Nil \\
\hline 2 & Gun powder & 17.65 & Nil & Sensitive \\
\hline
\end{tabular}

The activation energy $\left(E_{a}\right)$ was calculated for all stages of gun powder using Kissinger equation[10] and it was expressed by

$$
\mathrm{Ea}=-\ln \left(\mathrm{q} / \mathrm{T}^{2} \max \right) * \mathrm{RT} \max
$$

Where $\mathrm{q}$ is the heating rate in $\mathrm{K} \min ^{-1}, \mathrm{~T}_{\max }$ is the peak temperature in $\mathrm{K}$ and $\mathrm{R}$ is the universal gas constant $(8.314 \mathrm{~J}$ $\mathrm{K}^{-1} \mathrm{~mol}^{-1}$ ). The heating rate followed for all the stages of gun powder during thermal analysis was $283 \mathrm{~K}\left(10^{\circ} \mathrm{C}\right)$. The values of $\mathrm{E}_{\mathrm{a}}$ calculated using these parameters for gun powder were listed in Table 5

Table-V: The activation energy for Gun powder

\begin{tabular}{|l|l|l|}
\hline Gun powder at various stage & Peak $\left({ }^{\circ} \mathbf{K}\right)$ & $\begin{array}{c}\text { Activation energy } \\
\mathbf{K J} / \mathbf{m o l}\end{array}$ \\
\hline After preparation & 541.83 & 31.283 \\
\hline Shadow Shed & 540.88 & 31.212 \\
\hline Drying platform & 539.49 & 31.109 \\
\hline
\end{tabular}

The minimum energy required to initiate a combustion reaction is known as activation energy. The activation energy of a chemical reaction is usually expressed by Ea. The energy required for the combustion of gun powder after preparation is $31.283 \mathrm{KJ} / \mathrm{mol}$. The gun powder collected from shadow shed it is $31.21 \mathrm{KJ} / \mathrm{mol}$. The activation energy of gun powder from the drying platform is $31.109 \mathrm{KJ} / \mathrm{mol}$. It clearly understands that when moisture content present in the gun powder chemical composition, it needs more amount of energy to initiate the combustion reaction.

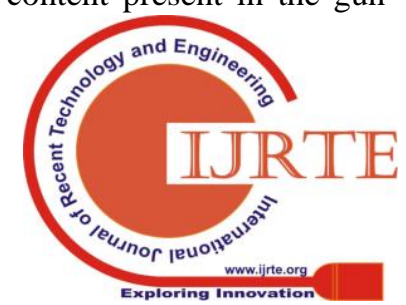


So the reduction of moisture content to reduce the activation energy and increase of moisture content to increase the activation energy. If more amount of heat can be given to the reaction leads to a fire accident. So existing high amount of moisture content increases the safety hazards and followed by accident.The thermal behavior of the gunpowder at various stages like after preparation, shadow shed and drying platform is given in Fig.1.

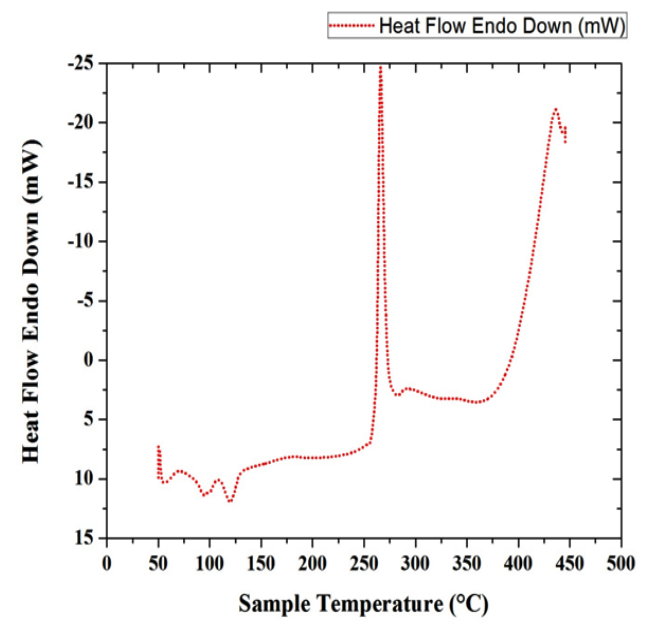

(a) After preparation

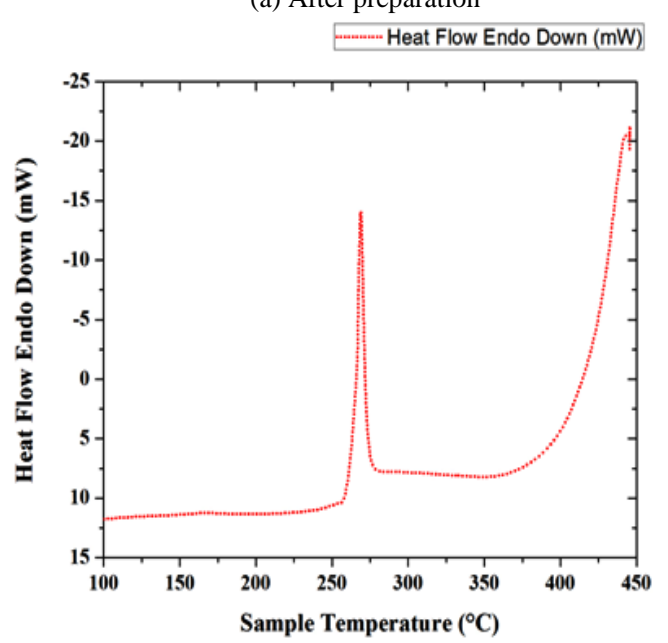

(b).Shadow Shed

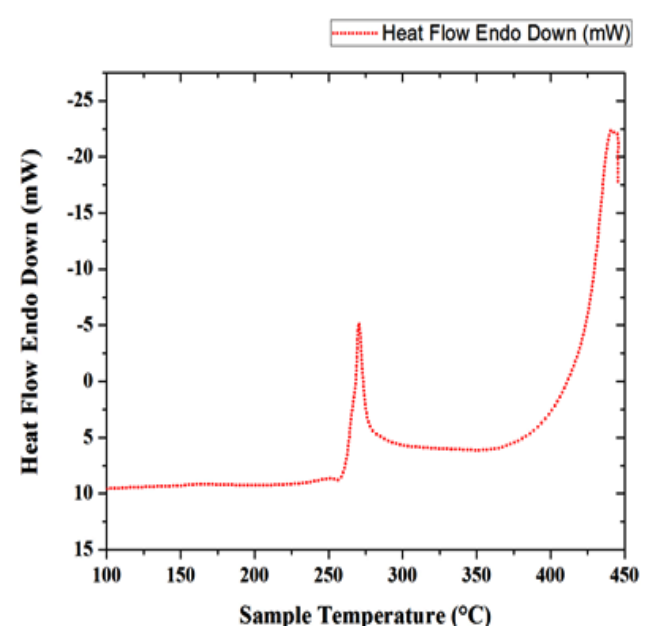

Drying platform
Fig. 1.DSC result for gun powder

\section{CONCLUSION}

Thermal decomposition behavior of gun powder composition is studied at different environment, the following observation is made.

- Thermal decomposition rate is higher when it is exposed to direct sunlight; the reason is due to immediate absorption of moisture content.

- Thermal decomposition rate is comparatively lesser, when it is exposed to sunlight under shadow shed; it is due to small removal of moisture content from gun powder composition.

- Activation energy is comparatively lesser, when it is exposed to sun light under shadow shed, it is due to large removal of moisture content from gun powder composition.

- The observation is also made from impact and friction sensitivity studies; it reveals that the flash does not occur for gun powder in pellet form. The gun powder chemical composition comes under sensitive category and safety aspect has been enhanced.

\section{REFERENCES}

1. S. P. Sivapirakasam, M. Surianarayanan, G. S. Venkatratnam and P. Nagaraj,"Hazard evaluation technique for Firework compositions," Indian Chemical Engineering Congress, Hyderabad," 19-22 December 2003, pp. 126.

2. S.Russell in "The chemistry of fireworks", Michael 2nd edition, RSC piublishing, 2009.

3. J. Conkling, "Chemistry of Pyrotechnics:Basic Principles and Theory", Taylor \& Francis, New York, 1985.

4. M. Yao, L.Chen, Yu, J., \& J.Peng, "Thermo analytical investigation on pyrotechnic mixtures containing $\mathrm{Mg}-\mathrm{Al}$ alloy powder and barium nitrate" Procedia Engineering, 45, 2012, pp.567-573.

5. S.V. Pakkirisamy, S.Mahadevan, S.S.Paramashivan, \& M.A. Baran, "Water-induced thermal decomposition of pyrotechnic mixtures-Thermo kinetics and explosion pathway," Journal of loss Prevention in the Process Industries, 30, 2014, pp. 275-281.

6. M.E Brown., \& R.A. Rugunanan, "A thermo-analytical study of the pyrotechnic reactions of black powder and its constituents," Thermochimica Acta, 134, 1988, pp. 413-418

7. X.L.Chen., Y.J.Wang, C.R.Wang, Hu, D. L., Sun, Y. X., \& Li, S. $\mathrm{S}$, "Burns due to gunpowder explosions in fireworks factory": a 13-year retrospective study. Burns, 28(3), 2002, pp. 245-249.

8. Y Li, W.Song, C. Xie, D. Zeng., A. Wang., \& M. Hu, "Influence of humidity on the thermal behavior of aluminum nanopowders," Materials chemistry and physics, 97(1), 2006, pp. 127-131.

9. Q. Xing, Z. Du., L.Zhao, \& Q.Yin, "Study of the environmental humidity influence on the thermal safety of the pyrotechnic compositions,". Procedia Engineering, 45, 2012, pp. 552-557.

10. R. Wharton, J. Harding, "An experimental comparison of three documented methods for the evaluation of friction sensitiveness," $J$ Energ Mater, 11, 1993, pp. 51-65.

\section{AUTHORS PROFILE}

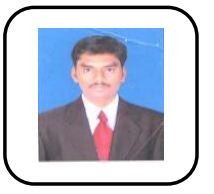

R.Manikandan obtained his B.E (MECH) in 2009 from the P.S.R Engineering College, Sivakasi, Tamilnadu, India. He completed his M.Tech (Industrial Safety Engineering) in 2014 at Mepco Schlenk Engineering College, Tamilnadu, India. Currently, he is working as a Assistant Professor in the Department of Mechanical Engineering, Kalasalingam Academy of Research and Education, Krishnankoil, Tamilnadu, India. His research interests include investigation of fireworks accidents and exposure of various experimental setup like frition, impact sensivity test, Noise level test and therhFalganlalysis test. 
I have completed in B. E in Mechanical Engineering and M.E. (CAD) from Alagappa Chettiar Government College of Engineering and Technology, Karaikudi, Ph.D (Machining of Metal of Matrix Composites) from Kalasalingam Academy of Research and Education, Krishnankoil in the year 2014, and thesis highly recommended by both the examiners. In the year 2018, I have received DST - AMT project for the worth of Rs 25, 72, 400 and completed one IEDC project for the worth of Rs 1, 00,000. I have published more than 25 journal papers (impact factor and Scopus cited) and more than 40 international conference papers.

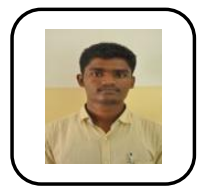

K.Subhash is a first year M.Tech Industrial Safety Engineering student, Department of Mechanical Engineering, Kalasalingam Academy of Research and Education, Krishnankoil, Tamilnadu, India

TABLE I. THERMAL EVENT OF GUN POWDER AT VARIOUS STAGES

\begin{tabular}{|c|c|c|c|c|}
\hline Sample & Dips/Peaks & Number & Temperature $\left({ }^{\circ} \mathbf{C}\right)$ & Thermal event \\
\hline \multirow{4}{*}{ After preparation } & \multirow{3}{*}{ Dips } & First & 86.89 & \multirow{2}{*}{ Endotherm - the transition of Sulfur } \\
\hline & & Second & 111.92 & \\
\hline & & Third & 320.42 & Endotherm - phase transition of $\mathrm{KNO}_{3}$ \\
\hline & Peak & First & 262.27 & $\begin{array}{l}\text { Exotherm - violent decomposition of gun } \\
\text { powder }\end{array}$ \\
\hline \multirow{5}{*}{ Shadow Shed } & \multirow{4}{*}{ Dips } & First & 50.28 & \multirow{2}{*}{ Endotherm - the transition of Sulfur } \\
\hline & & Second & 115 & \\
\hline & & Third & 325 & Endotherm - phase transition of $\mathrm{KNO}_{3}$ \\
\hline & & Fourth & $\sim 380$ & $\begin{array}{l}\text { Exotherm - thermal decomposition of } \\
\text { carbon content }\end{array}$ \\
\hline & Peak & First & 263.93 & $\begin{array}{l}\text { Exotherm - violent decomposition of gun } \\
\text { powder }\end{array}$ \\
\hline \multirow{4}{*}{ Drying platform } & & First & 52 & \multirow[t]{2}{*}{ Endotherm - the transition of Sulfur } \\
\hline & & Second & 86 & \\
\hline & \multirow{2}{*}{ Peaks } & First & 265.25 & $\begin{array}{l}\text { Exotherm - violent decomposition of gun } \\
\text { powder }\end{array}$ \\
\hline & & Second & $\sim 410$ & $\begin{array}{l}\text { Exotherm - thermal decomposition of } \\
\text { carbon content }\end{array}$ \\
\hline
\end{tabular}

